\title{
Drug manufacturing and access to medicines: the West African story. A literature review of challenges and proposed remediation
}

\author{
Abigail A. Ekeigwe(1)
}

\begin{abstract}
It is the right of all humans to have access to safe, quality and effective medicines. This article seeks to expound on the problems of drug manufacturing and challenges of accessing medicines in West Africa, and evaluate the strategies being adopted by international developmental partners and the governments to address them. West Africa is uniquely diverse in culture (having English, French and Portuguese speaking people) but generally affected by the same diseases (e.g., malaria, HIV/AIDS, and Tuberculosis). In this developmentally beleaguered region, drug development and manufacturing are still stuck in their embryonic stages where medicine distribution is chaotic and insufficiently regulated. An enduring question is why investment in research and development in medicines for neglected tropical diseases and manufacturing is still very low in Africa and in particular West Africa. In this article, we look at how these vulnerabilities are exploited by unscrupulous merchants, leading to massive influx of fake and substandard medicines to the supply chain, making it difficult for the rural, voiceless poor to access quality safe medication. Through an examination of current research and published works by the World Health Organization (WHO), the United States Pharmacopeia (USP) and other international development partners in Africa, first hand interactions with manufacturers, medicine regulators, regulatory consultants, and the patients, as well as from personal observations, the article crystallizes the major issues and challenges to drug manufacturing and access to quality, safe, and effective essential medicines in West Africa. This article also examines the strategies and policies being implemented to salvage the situation. It is irrevocably clear that solving the challenges of providing safe medication to West Africa is a collective responsibility - the government (through legislation, strategic regulations and policies), medicines manufacturers (adoption of Good Manufacturing Practices and ethics), regulators (through persuasion and enforcement of rules), regulatory consultants, the patients (empowered, informed about their rights and courage and willingness to report drug reactions and discernible counterfeiting), the international development partners and all other stake holders in the health care sector have roles to play in ensuring that the public has access to quality safe and efficacious medicines.
\end{abstract}

Keywords: Medicines, Access, Safe, Quality, Effective, Substandard, Falsified, Challenges 


\section{Introduction}

West Africa is made up of 15 countries (Benin, Burkina Faso, Cape Verde, Cote D'Ivoire, Gambia, Ghana, Guinea, Guinea-Bissau, Liberia, Mali, Niger, Nigeria, Senegal, Sierra Leone and Togo), 3 main language groups (English, French and Portuguese) all belonging to a Regional Economic Community called ECOWAS (The Economic Community of West African States) and a regional health organization called WAHO (West African Health Organization). Within ECOWAS is another regional economic block for the Francophone countries (Benin, Burkina Faso, Cote d'Ivoire, Guinea-Bissau, Mali, Niger, Senegal, and Togo) called West African Economic and Monetary Union having UEMOA as the acronym in French. The countries in ECOWAS have very limited economic resources. It is a socially, economically, politically, and culturally diverse region with a rapidly growing population.

In 2007, according to the Organization for Economic Cooperation and Development-OECD report, the population of the ECOWAS region (including Chad and Cameroon) was put at 316 million. It is expected to reach 400 million by 2020 and 'exceed 500 million between 2030 and 2035' (ECOWAS-SWAC/OECD 2007). The United Nations has projected that the population of Nigeria, a country in ECOWAS, will surpass that of the United States shortly before 2050 (United Nations Department of Economic and Social Affairs Population Division 2017). Eleven of the region's countries are grouped as Least Developed Countries (LDC) by the United Nations Conference on Trade and Development (UNCTA) (United Nations Conference on Trade and Development 2016). In the African Human Development Index (HDI) ranking, 2 countries (Ghana and Gabo Verde) are ranked as medium in human development while others are ranked as low human development (United Nations Development Program 2016). However, the countries in West Africa are beleaguered with similar diseases and issues affecting the manufacturing and delivering of medicines in the region. In this article we will attempt to answer the following questions - what are the challenges of manufacturing medicines in West Africa? Why is access to medicines in this region still a huge intractable challenge? (Fig. 1).

There is a raft of critical issues affecting medicines manufacturing and access in West Africa. The list below is not exhaustive but gives the reader an insight into the spectrum of challenges facing the region. The list is developed from examining literature, interactions with stakeholders, and anecdotal evaluations. A few of these challenges will be expounded on later in the article.

\section{Limited availability of human resources}

There is paucity of trained and competent personnel both in the regulatory and manufacturing fields - notice that it is not paucity of "schooled" personnel but "trained" and "competent". The few that are trained are poorly remunerated and thus not motivated by their work environment and remuneration, leading to "brain drain" - professionals seeking job outside West Africa. The distribution of trained and qualified health care providers is skewed. Most are in the urban areas whereas the disease burden is heavier in the rural areas. This situation is further exacerbated by physical insecurity in the rural areas. For fear of being kidnapped or killed, healthcare professionals avoid areas that are prone to terrorist or kidnapping groups. This impedes access to medicines in these areas.

\section{Challenges in medicine manufacturing}

The challenges of having robust and continuous supply chain in West Africa are compounded by the following:

- Lack of good Infrastructure such as transportation systems, communication networks and constant power supply (The African Union Commission 2012).

- The health care sector is highly dependent on drugs, vaccines, medical devices, and diagnostics externally developed and procured, especially from India and China, denying opportunity for indigenous learning curve.

- Raw materials and equipment needed for the production of medicines in West Africa are mostly imported. There is only one small-scale manufacturer of active pharmaceutical ingredients located in Ghana (West African Health Organization 2018). There is very little capacity for the production of any of the raw materials or equipment (The African Union Commission 2012).

- Manufacturers in the region are finding it difficult to attain WHO (World Health Organization) pre-qualification because of financial and technical constraints (United Nations Industrial Development Organization 2015). Technical constraints include, but not limited to skilled personnel, required equipment, and reference materials. The financial constraints have two prongs - the resources (local capital formation) are scarce and foreign exchange rates are tipped against importation i.e. local currencies have very low equivalence rates to currencies accepted in international trade.

- There is also a dearth of skilled technical personnel in drug development and manufacturing (The African Union Commission 2012).

- Medicine manufacturing for West Africa is a tough business with very small profit margins - in capitalism capital preferentially flows to destination with high return on investment, unless some policy 


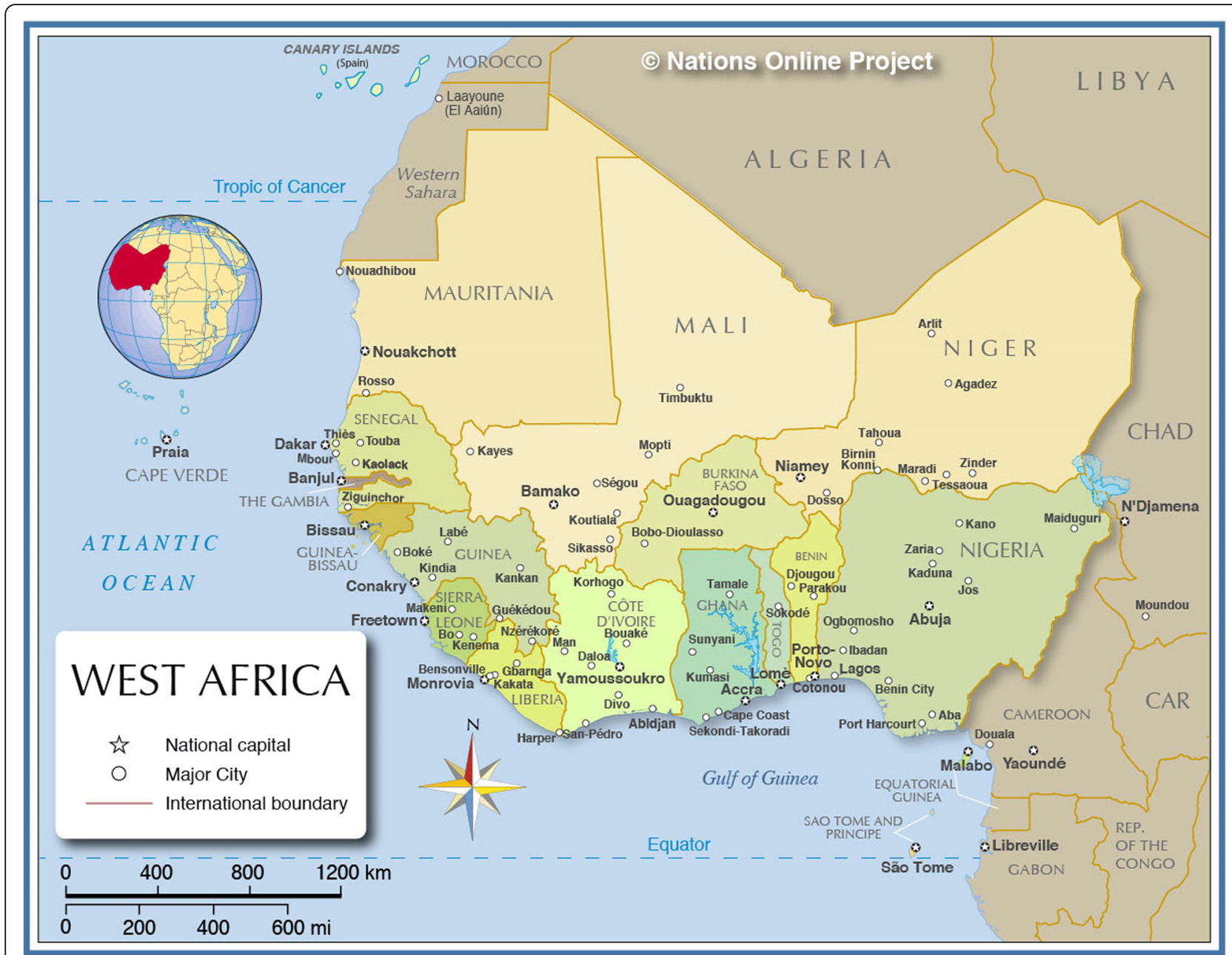

Fig. 1 The countries of West Africa. Source - (Political Map of West Africa - Nations Online Project 2019). Free online resource

intervention compels otherwise (West African Health Organization 2014)

- The West African region does not have any clinical research organizations and bioequivalence centers. This hampers the introduction of both quality generics and branded medicines to the market (The African Union Commission 2012).

\section{Government apathy}

Overall, there are low investments in the healthcare sector by the governments.

- Lack of government incentives to promote the local manufacture of medicines. Incentives in the form of free land for setting up manufacturing outfits (e.g. Economic Free Trade Zones), funding of research and development, establishment of technology incubation centers for pharmaceutical manufacturing, tax holidays and/or rebates, giving of cheap loans to manufacturers, are missing or very few in West Africa (The African Union Commission 2012).

- Low investments in Research and Development $(R \& D)$. Health researches are very few and outcomes and recommendations from the few health researches are not being implemented. A number of studies show that the funding of R\&D in Africa and West Africa is low (Nwaka et al. 2010; Berger et al. 2010; Defor et al. 2017). African governments committed to spending $1 \%$ of their health budget on research but only few are striving to meet that commitment. Only a few countries in West Africa have R\&D expenditure data for some years on the Gross domestic expenditure on R\&D (GERD), GERD as a percentage of GDP (Gross Domestic Product), GERD per capita and GERD per researcher in the United Nations Educational, Scientific and Cultural Organization (UNESCO) Institute for Statistics (UIS) database for expenditures in R\&D. 
- Inadequate implementation of existing policies and blasé regulatory enforcement. An example is the implementation of the Primary Health Care (PHC) policy in the region. This policy aimed at ensuring equity in access to quality healthcare services has suffered some setbacks due to poor implementation. A case study on Nigeria conducted by WHO revealed a lot of gaps and challenges to the implementation of this laudable policy. The conclusion of the case study is "Summarily, the Nigeria PHC system suffers from fragmented services, weak referral systems and poor infrastructure, and there are serious gaps in access to basic health services ... Most health centers no longer have functional drug revolving schemes, resulting in shortage of essential and critical medicines and commodities at point of service delivery" (Uzochukwu 2017)

- The borders of the region are very porous leading to smuggling of substandard and falsified medicines into the region.

- Non-Availability of adequate health care facilities in the rural areas, and inequitable spatial distribution of health services and facilities (WHO 2015). Majority of the health facilities are located in urban areas. Residents of most rural areas travel miles to get to the nearest health facility (PHC), which are barely resourced with qualified personnel, equipment and medicines (Uzochukwu 2017).

- Poor availability of essential medicines especially in the public sector is a key barrier to the access of essential medicines especially by the poor and low-income earners (Dying from lack of medicines | Africa Renewal Online 2019).

- Low health care financing by the governments. National Insurance schemes have very low coverage and are inaccessible to the majority. Thus there is high out-of-pocket expenditure by the populace (WHO Regional Office for Africa 2013).

- Weak public private partnerships in the health sector (West African Health Organization)

\section{Patents}

Patents restrictions and inability of locals to gain patents is a barrier to accessing medicines in developing countries like the West African countries (Sampat 2009).

\section{Prices of medicines}

Finished pharmaceuticals are very expensive due to high tariffs, taxes and distribution costs (World Health Organization 2011).

\section{Poor medicines regulatory capacity}

The regulatory capacity and capability in the region is very low - regulators are inexperienced (Moran et al. 2010) and poorly rewarded - clear prescriptions for weak enforcement. In addition, there are unclear regulatory requirements for the issuance of marketing authorization (West African Health Organization 2014); the lack of reciprocal recognition of regulatory processes between Anglophone, Francophone and Lusophone countries putting constraints to human resource mobility and access to quality and affordable medicines in the region (West African Health Organization 2014); Inadequate cooperation and vulnerable trust among ECOWAS Member States (West African Health Organization 2014). This affects the potential for the portability of regulation across borders. The medicines distribution and supply channels are chaotic especially in the private sector. Public sector distribution is through the Ministries of Health. However, the private sector distribution channels are not defined and it is very difficult to track. In these regions highly regulated prescription drugs may be found sold in open markets, many are Substandard and Falsified (West African Health Organization 2014). The proliferation of Substandard and Falsified (SF) medicines, in most cases is oppressing good products out of the market, and further discouraging investments in research and development. The health information systems are weak to non-existing. Thus communication and knowledge sharing within the region is low. There is duplication of efforts and resources contributing to diseconomy in the drug supply chain of the region.

\section{Low literacy level of consumers}

There is low Literacy level of medicines consumers (United Nations Educational, Scientific and Cultural Organization Literacy and Non-Formal Education 2018). UNESCO Institute of Statistics (UIS) in its 2017 report showed that the average literacy rate for adults (above 18 years) in most countries in West Africa is below 50\% (UNESCO Institute for Statistics - Literacy 2019). They are about the worst rates in the world. As we will discuss later, access involves the rational use of medicines. The low literacy level affects the rational use of medicines, affecting the level of awareness needed to cultivate rational, discriminate receptivity for medicines (low literacy level affects the general level of safe medication awareness which in turn affects capacity for rational use of medicines).

\section{Corruption}

The list will be incomplete without mentioning the monster preventing the development of all sectors of West Africa - corruption. It has permeated the fabric of the society. Health care professionals are rarely keeping their obligations to the people because of corrupt practices. Many laudable ideas and projects have died in the cold 
hands of this of systemic corruption in African societies. The Transparency International corruption perception report for 2017 shows that countries in this region are amongst the most corrupt in the world (Transparency International - Corruption Perceptions Index 2017).

It is against this backdrop that the majority of the populace of West Africa struggle to survive the diseases plaguing the region. Common health conditions of concern in the region are malaria, tuberculosis, HIV/AIDS, childbirth complications for mothers and Neglected Tropical Diseases (NTD) like food-borne trematodiases, lymphatic filariasis, schistosomiasis, and soil-transmitted helminthiases (World Health Organization Neglected Tropical Diseases 2018). In addition to these infectious diseases, cases of non-communicable chronic diseases are on the rise. Thus we have a state of "double burden" - a situation where the health systems will have to be responsive to both infectious and noncommunicable chronic diseases - as stated by the WHO World Medicines Situation 2011 - Global Health Trends: global burden of disease and pharmaceutical needs (WHO 2015). The region is also faced with severe poverty and malnutrition. A recent World Bank report on poverty in Africa shows that the "poverty population" in Africa has increased. "The World Bank show that the share of Africans who are poor fell from 57 percent in 1990 to 43 percent in 2012 -.-Nonetheless, even given the most optimistic estimates, still many more people are poor because of population growth: more than 330 million in 2012, up from about 280 million in 1990." (Beegle et al. 2016). This in turn has led to hunger and malnutrition (Africa Hunger Facts, Africa Poverty Facts - World Hunger News 2019). It is reasonable to say that malnutrition is a form of disease, or at least a veritable disease substrate.

International development partners such as WHO, UNIDO (United Nations Industrial Development Organization), UNESCO, USP, WAHO, the European Union, World Bank, Bill and Melinda Gates Foundation are involved in projects to address some of these issues. They are working with the African governments and institutions to improve access to safe, quality and effective medicines. This article will highlight some of these efforts.

The next portions of this article will delve deeper into some of the issues affecting drug manufacturing and access to medicines in West Africa.

\section{Challenges to access and distribution}

The 8th goal of the Millennium Development Goal (MDG) states, "In cooperation with pharmaceutical companies, provide access to affordable essential drugs in developing countries". The indicator for this goal is "Proportion of population with access to affordable essential drugs on a sustainable basis" (Millennium development goals indicators 2000). Note that these MDGs were agreed to in the year 2000 by the
United Nations Millennium Assembly and set out in 2001 as a global framework to shape the planning and monitoring of development efforts, particularly in low income and developing countries. They suggest that such countries should strive to achieve a number of quantified goals to reduce extreme poverty, disease, and deprivation by 2015 .

Thus significant access to quality essential medicines for developing countries as in West Africa is a goal that should have been met by 2015 if the MDGs were fully realized. The MDG Gap Task Force Report 2015 showed that access to essential medicines remains a problem for low and lower-middle income countries (United Nations 2015). However, according to the report, significant efforts were made to increase treatment access especially for diseases such as HIV/AIDS, malaria, and tuberculosis.

The Sustainable Development Goals (SDG) is the current program set by the United Nations to help national developments. SDG number 3 is "Ensure healthy lives and promote well-being for all at all ages" (Sustainable development goals 2018). To achieve this, the SDG targets "access to quality essential health-care services and access to safe, effective, quality and affordable essential medicines and vaccines for all" by 2030 (Sustainable development goals 2018). Will this be achieved? This is a difficult question to answer. The following questions are raised and will be addressed and discussed below Why has access to quality, safe and effective medicines yet to be realized in West Africa? What challenges are there to "access"? How can these challenges be mitigated to ensure that SDG goal 3 is achieved in West Africa?

Access is defined as having medicines continuously available and affordable at public or private health facilities or medicine outlets that are within $1 \mathrm{~h}$ walk from the homes of the population (United Nations Development Group 2003). It is characterized by four cardinal attributes (WHO) - rational selection, sustainable financing, affordable pricing and reliable health and supply system (World Health Organization 2004). The challenges to access and distribution of quality essential medicines in West Africa will be discussed in the context of these four characteristics of access.

The MDG goal related to providing access to affordable essential medicines (MDG 8e) is evaluated and monitored by the proportion of population with access to affordable, essential drugs on a sustainable basis, which is, the percentage of the population that has access to a minimum of 20 most essential drugs (United Nations Development Group 2003).

According to the WHO, rational selection of medicines involves choosing medicines appropriate to the country's health situation on the basis of their effectiveness, safety and cost. Institutionalizing rational choice involves using Essential Medicines Lists (EMLs), based on the best available evidence on local disease burden, 
efficacy, safety and cost of treatment for those diseases (WHO 2015). The government of each country, through the ministry of health, sets up a committee made up of physicians and pharmacist to formulate the EML for that country. For example the government of Nigeria reviewed the EML using a committee of this nature (Federal Ministry of Health Nigeria 2016). The same is true for other countries in the region.

To help countries, the WHO published its first model EML in 1977. Countries were expected to develop national EML using this model and taking into consideration the disease gradients and prevalence in their countries. Rational selection of drugs for the treatment, promotion and protection of the health of citizens of a country were to be based on the EML of that nation. However, studies have revealed that the EML of countries are not only different from the WHO EML but also amongst countries having the same disease patterns (Mugiraneza 2009). Thus the logical reasoning is this if the EMLs developed by West African countries are deficient or not congruent with the WHO Model List, and markedly different among themselves despite having similar disease pattern, how can rational selection be made from it? And if rational selections were deficient, then access would have been impaired. This is because procurement of medicines by the government is based on the EML. The government procures medicines centrally through the ministry of health and then distributes them to all its health facilities in the country. It has also been noted from personal observations and discussions with pharmacists in the region that most prescriptions are not based on the EML of their respective countries. Healthcare professionals are largely not familiar with the EMLs. Access to essential medicines as defined by the MDGs is thus further impaired.

Sustainable Financing of medicines is yet an illusion and a remote prospect in many West African countries. The primary sources of healthcare financing are private. Supplemental sources are from international donor agencies such as the Bill and Melinda Gates Foundation, The PEPFAR (President's Emergency Plan For Aids Relief) funds, and the Global Funds. These international donors fund medicines and healthcare programs that address diseases of egregious public health concern such as HIV/AIDS, malaria, tuberculosis, and poliomyelitis.

For non-communicable diseases such as various cardiovascular diseases or cancer the populace are solely responsible for their care. The National Health Insurance schemes do not have a wide coverage. The government spends very little on medicine procurement and financing of the healthcare systems. The populaces pay out of their pocket for medicines and other healthcare services. In many instances, the monthly cost of medication is greater than the monthly disposable income of the patients.
(World Health Organization Global Health Expenditure Database 2018). Thus without government interventions or insurance, many persons in West Africa are left without access to essential drugs. Out-of-pocket expenditure on healthcare is a major indicator used by the WHO to measure the equity of healthcare systems and the extent to which accessing healthcare depends on private abilities. Private expenditure on health has led to the impoverishment of many households in West Africa as they will have to sell off assets, including artisanal tools used in income generating trades, to offset healthcare bills (African Health Stats 2016). Invariably without such tools to support their trade the families only fall steps to miserable poverty and more incapable to afford medicines.

The 2013 report of the WHO African region states -"The Member States of the African Region of the WHO are on average still far from meeting key health financing goals such as the Abuja Declaration target of allocating $15 \%$ of the government budget to health. Outof-pocket expenditure is still higher than $40 \%$ of the total health expenditure in 20 of the 45 countries studied, and in 22 countries the total health expenditure does not reach even the minimal level of US $\$ 44$ per capita defined by the High Level Task Force on Innovative International Financing for Health Systems (HLTF). Only three countries have attained the Abuja Declaration and HLTF targets" (WHO Regional Office for Africa 2013). The situation is no different today. The 2018 budgetary allocation to health by Nigeria is $3.9 \%$. The highest allocation to health since the Abuja declaration has been 5.95\% (Adepoju 2017). The WHO country report on Nigeria in 2015 also corroborates this statistics. According to the report the expenditure on health by Nigeria is $3.7 \%$ of the GDP in 2014 (World Health Organization Nigeria 2018). This is grossly inadequate. The situation is no different in Gambia, where the budgetary allocation to health is $11 \%$ of the total government budget between 2010 and 2011. 65\% of their healthcare funding is from external sources and thus not sustainable (African Health Observatory 2013).

Prices of medicines in West Africa are not affordable for many because of the poverty levels. A large proportion of medicines used in the region are imported. The local manufacturers utilize active pharmaceutical ingredients imported mainly from China and India. Thus, fluctuations in the exchange rates of currencies ultimately affect the cost of medicines. From personal observations the 2015 increase in the exchange rates of the Naira to the Dollar in Nigeria resulted in multiple increases in the prices of medicines in some instances. For example the price of a brand of Amoxicillin and Clavulanic acid tablets increased by over $150 \%$. In addition to importation costs, there are other domestic price addon's costs such as wholesale and retail margins. Prices 
also increase between the ultimate patients and the factory/importer due to logistics costs, tariffs and taxes, and other hidden costs in the medicines supply chain. Since these add-on costs adversely impact the ultimate cost to the patient, governments should try to influence the relevant factors. However, this is not the case in West Africa. The governments have not instituted any form of price controls because of inclination to free market regime, which Western governments promote. For example in Cameroon, without price control, a complete treatment dose course for peptic ulcer costs "almost twice the monthly wage of a government employee" (Creese 2003). It is clearly not generally affordable. Access again is affected.

Reliable medicine supply chains have two primal components, namely, procurement and distribution systems. Public procurements done by the government through the Ministries of Health are fraught with many challenges ranging from inadequate quantification, nontransparent contract award process to inefficient supplies, receipt and storage processes at the Federal medical stores. Medicines are essentially procured by private pharmaceutical industries and businesses as vendors to the government. Reliable health and supply systems are limited, especially in the rural and sub-urban areas of the region. Ironically, a major proportion of the population resides in the rural and sub-urban areas (Population | West Africa 2019). Some communities will need to travel for hours before accessing any proper health care facility. This has led to the proliferation of untrained, unqualified and unregulated providers of healthcare supplies and services. This in turn has caused indeterminate undocumented mortalities.

In addition, anecdotal evidence abounds that there are no defined distribution channels for medicines in West Africa (The African Union Commission 2012). Distribution is the system by which medicines get to the ultimate target destinations (the patients) from their origin (the manufacturing site). An efficient and effective medicines distribution system affects time-to-patient cycle, affecting timely access to essential medicines at all levels of the health system and possible recalls of medicines when necessary. Distribution can be either by the government through Federal medical stores to government owned health institutions or privately by the importers or manufacturers via their own distribution channels to hospitals and pharmacies. A high proportion of medicines are distributed via these private channels and they are highly chaotic and unregulated.

It is clear from the forgoing that access to essential medicines in West Africa is very limited. This is further complicated by the prevalence of Substandard and Falsified (SF) medicines as discussed in the next section.

\section{The impact of substandard and falsified drugs on quality care}

\author{
A true Story- "The Narrow Escape of My Sibling From \\ Death" as related by Abigail Ekeigwe (Author)
}

She is a young woman aged 35 years. She is pregnant for her 3rd baby. On October 10, 2017, she gave birth to a baby boy. All went well. However, after $2 \mathrm{~h}$, she started bleeding (postpartum hemorrhage). The oxytocin injection administered to her did not elicit the expected uterine contractions. She was immediately taken to the theatre. She was opened up. The doctors tried to ascertain the causes. All seemed okay. But she was still bleeding! She narrowly escaped death! But for the expertise of the doctors and other health care professionals, it would have been a tragedy. This near death situation happened in one of Nigeria's best hospitals in Lagos. Root cause: SF medicine. If it could happen here, with their entire stickler for best practice, then one can only imagine what happens in the rest of the hospitals and rural regions.

This is a daily story of the result of substandard and counterfeit medicines in Africa.

The use of Substandard and Falsified (SF) medicines is worse than not using any medicines at all. Why? If one does not use any medicines at all, you are left with only the disease condition, however, if one uses SF medicines, in addition to the disease condition, one may be left with all the effects of SF medicines as highlighted in this part. The consequences of counterfeit medication are simply indeterminate.

SF medicines especially for public health diseases such as malaria, HIV/AIDS, tuberculosis; and for maternal and child health such as oxytocin injection and amoxicillin suspension are prevalent in West Africa. The World Health Organization, in 2015, conducted a survey on the quality of medicines identified by the United Nations (UN) Commission on Life-Saving Commodities for Women and Children (UNCoLSC). In the study, selected drugs from the list of 13 life-saving commodities were tested against predetermined quality criteria. The survey covered 10 countries - 2 were from West Africa i.e. Nigeria and Burkina Faso. Nigeria and Burkina Faso had $35 \%$ and $31 \%$ failure rates respectively. Amongst the medicines evaluated, the highest failure rate is from oxytocin (64\%) (World Health Organization 2015). This is a dire situation. It literally means that about one third of these life-saving commodities circulating in the markets of West Africa are substandard or counterfeit. It is then not surprising that West Africa, especially Nigeria contributes significantly to the total global statistics of 
maternal death by postpartum hemorrhage (World Health Organization Global Health Observatory 2018).

There are many multifaceted and complex factors causing the high prevalence of Substandard and Falsified medicines in West Africa. Some of which are -

- The financial returns are very high for this activity because the demand for medicines is high largely due to the heavy disease burden. Also contributing to this is the huge difference between the cost of production of these SF medicines and their selling price (they are usually sold at the same price as the equivalent quality medicines).

- Prescription drugs are expensive and there is poverty and economic hardship in the region. This provides a good substrate for exploitation by counterfeiters

- Counterfeiting is relatively an easy act to commit in West Africa because: movement of goods and people across countries is relatively easy (citizens of countries in this region do not require visas to travel within the region), gatekeeping at regional boundaries is porous, there is little likelihood of being detected and or caught once the counterfeit medicines have been introduced into the medicines supply chain, medicines regulatory framework is weak (World Health Organization 2010) and there is poor communication between National Medicines Regulatory Authorities (NMRAs) .

- Inefficient regulatory systems also encourage counterfeiting. The "good" companies that come forward to register their products are bogged down with too many inefficient regulatory processes, preventing their good products to reach the markets on time, thus giving way to counterfeiting. Counterfeiters take advantage of any gap in the supply of medicines to the market. Regulatory overload has to be balanced with ensuring quality. When artificial scarcities create mass hysteria counterfeiters exploit the opportunity to insert their products in the market because desperate people would less likely question the quality of medicines.

- The penalties for counterfeiting are not strong enough to positively influence behavior. Counterfeiters know this and simply rationalize and normalize legal penalties as routine cost of business. (COUNTERFEIT AND FAKE DRUGS AND UNWHOLESOME PROCESSED FOODS (MISCELLANEOUS PROVISIONS) ACT 2018)

The impact of counterfeit and substandard drugs on quality care will be discussed from the perspective of the patient, the pharmaceutical company, the health care provider and the community.

Not only do substandard or counterfeit drugs fail to cure or give expected relief. They also cause definite harm to the patient such as organ damage, development of resistance to medicines, long(er) hospital stays with huge adverse economic impact and even death (Blackstone et al. 2014). Above all, the drug failure causes psychological illness manifested in despondency for failed expectations - because as the common saying goes "expectations postponed make the heart sick."

Pharmaceutical companies are having a hard time dealing with counterfeiting because they are dealing with nondescript indeterminate situations. The pattern of counterfeiting is always changing in unpredictable manners. Counterfeiting is some times insidious in nature, such as when unscrupulous employees of the pharmaceutical companies work for or cooperate with the counterfeiters. They are spending millions in the fight against counterfeiting of their products. Unfortunately, due to the endemic institutional weakness in Africa, law enforcement is not sufficiently vigorous and so justice is not speedily done to discourage counterfeiting. Litigations can go own for decades and until interests attenuate and the matter goes into obscurity, unresolved. SF products take away substantial part of the market share of the branded or quality generic drugs and detract their profitability. Most importantly, they can also lead to a total discrediting of the brand and company with blemish causing customer paranoia. When patients and health care providers consistently observe treatment failure from the use of medicines that are unknowingly counterfeit, they are less likely to prescribe or use that brand or generic in the future. So gradually the SF medicine weakens the legitimate brands and may, eventually drive the brand out of the market. Africa has witnessed many such parasitic symbioses in the industry that drove away iconic brands from the market.

In healthcare more than in all other industries, trust is a critical, defining fundamental. Trust in healthcare providers is eroded when patients fail to get better by the inadvertent use of counterfeit or substandard products on the patient. Once a brand is tainted with counterfeiting the doctors and patients recoil into protective mode and avoid the brand. The patient may believe that treatment failure is due to wrong diagnosis or prescription by the healthcare provider rather than substandard and fake medicine.

Millions of man-hours of work are lost to time offs due to prolonged illness of patients using substandard and falsified medicines. This is a loss to the community. The community has also lost to the cold hands of death, millions of children and youths.

Substandard and Falsified medicines is the blight of medicines supply chain in West Africa.. Vigorous, reliant 
regulatory and enforcement activities are needed to contain this menace. Unfortunately, the institutional structures and instruments are weak.

\section{Medicines regulatory challenges in West Africa}

Most countries in West Africa either have a body (unit or department), which performs the functions of a National Medicines Regulatory Authority (NMRA), or they have a full fledge NMRA (World Health Organization 2010).These NMRAs are however at different stages of development or maturity. The overall goal or mandate of these NMRAs is no different from their counterparts in other regions - protecting and promoting the health of their citizens by ensuring that only quality, safe and effective medicines are manufactured locally or imported, promoted, distributed, sold and accessed by the people through the enforcement of legislation, rules and principles.

According to the WHO, the core functions of NMRAs are issuance of marketing authorization (MA), licensing of manufacturing establishments, imports and export control, inspection of manufacturing premises and distribution channels, market surveillance (product quality monitoring, pharmacovigilance, control of drug promotion and advertising), quality control, and oversight of clinical trials on drugs and other pharmaceuticals (World Health Organization 2010). To meet these mandates and effectively and efficiently dispense its regulatory services to the public, an NMRA should have adequate capacity including a clear legal mandate, governance structure, quality management systems, human and financial resources, regulatory infrastructure and fair, vigorous enforcement activities (unfair enforcement activities are unnecessarily retributive instead of being encouraging, restorative and edifying [promoting learning] in the industry).

This section of the article looks at medicines regulatory challenges from two perspectives - the challenges faced by regulators crystallizing the general focus of regulatory stewardship in the region and the regulatory hurdles pharmaceutical companies must overcome to do business in and supply drugs to West Africa.

Anecdotal evidence, interactions with regulators in the region and the literature have identified the following challenges faced by regulators and NMRAs in the West African sub region.

Weak legal structures - All NMRAs in West Africa have some form of legal frameworks. However, some legal frameworks can be compared to an old spider's web, with unclear definitions of responsibilities, resulting in regulatory gaps and overlaps with other agencies in their respective countries. In many countries not all regulatory functions are undertaken by NMRAs. For example in Nigeria, the licensing of manufacturing establishments is done by another regulatory agency in the country - The Pharmaceutical Council of Nigeria. However, in Ghana, the licensing of pharmaceutical manufacturing firms is done by the NMRA. Also the laws or regulations guiding the NMRAs in their regulatory functions require reviews to address global trends in regulatory sciences and adjust the penalties for contravening any of such laws. For example, there are no regulations on data integrity in the region and the penalties for contravening existing regulations are ridiculously not punitive enough to discourage deviant actions. (In Nigeria, the penalty for contravening the law on Counterfeit And Fake Drugs And Unwholesome Processed Foods (Miscellaneous Provisions) Act is a fine of 500,000 Naira, an equivalent of $\$ 1,390$ by the exchange rate of a dollar to 360 Naira; or a jail term of 5 to 15 years or both) (COUNTERFEIT AND FAKE DRUGS AND UNWHOLESOME PROCESSED FOODS (MISCELLANEOUS PROVISIONS) ACT 2018). Thus the NMRAs enforcement capabilities are impaired and blighted by old weak laws and, in some cases, anachronistic laws and desuetude not relevant and effective for regulating in a modern civilization.

Human Resources - Most NMRAs do not have the requisite portfolio of competent personnel to execute its mandate. Competency is lacking in the areas in critical regulatory practice areas, such as dossier review, especially for New Chemical Entities (NCE), evaluation of bioequivalence data, inspection of facilities, pharmacovigilance and post-marketing surveillance, monitoring of clinical trials and quality management systems. A typical scenario in most NMRAs in West Africa is that an individual with a science degree in desperate search of job drifts into a medicines regulatory position by virtue of being hired into the NMRA, sometimes through political cronyism. Most regulators at the beginning of their careers do not have any exposure to regulatory practice or pharmaceutical education with even less knowledge about regulations. In many cases, on the job training is lacking and they stumble their way through learning on the job.

Sometimes they may be fortunate to get training from their employers, WHO, USP and other international development partners later. And for the first time they become conscious of the enormous task they are handling - protecting the lives of people through regulations and informed regulatory decision. These experiences have led to the understanding that hiring and training the right talent is critical for the agenda of the NMRA's. Developing expertise requires extensive deliberate practice (Clark 2008) by knowledgeable people. In most of Africa the falling standard of education means the knowledge is not being properly acquired. And because of institutional inefficiencies employees do not have the right environment to engage in deliberate practice to develop 
expertise. This is a big problem given that it takes a long time to become an expert (Levitin 2008).

Non-implementation of Quality Management Systems (QMS) in NMRAs - Almost all NMRAs in West Africa operate without Quality Management Systems in place. A WHO report on the assessment of medicines regulatory systems in sub-Saharan Africa published in 2010 stated that "Quality Management Systems covering regulatory procedures .... are generally absent" (World Health Organization 2010). The situation has not improved much in 2018. Only the Ghanaian NMRA has gotten accredited to ISO 9001:2015. A few other countries e.g. Nigeria are in the process of establishing QMS and may be accredited in the near future. Thus NMRAs are not consistent, effective and efficient in their operations and decision-making processes. Decision-making processes are not transparent. QMS are the bedrock for the provision of quality services to both the public and the pharmaceutical companies.

Paucity of financial resources - All countries in West Africa although developing economically, but are still underdeveloped. One of the known consequences of this underdevelopment is the inability to engage in effective capital formation (resource mobilization). Resources are scarce and very limited. Nothing in the worldview of leaders motivates them to adequately fund NMRAs because the benefits are intangible in nature and difficult to evaluate. The consequences of poor medicines regulation are remote and thus the relationship is not seen quickly between poor financing of NMRAs and the quality of life of the populace. Poor financing of NMRAs leads to poor functioning of NMRAs which in turn leads to poor access to quality, safe and efficacious medicines and therefore treatment failures and low quality of life of the populace (Ball et al. 2016).

Infrastructure - Physical facilities, vehicles and other tools to carry out regulatory functions such as post marketing surveillance and premises inspections are either inadequate or not available. Internet and computer technology infrastructure are inadequate or nonexistent in most West African countries - this hinders communication within the ECOWAS sub-region (World Health Organization 2010).

Other challenges include - shortage of quality control laboratories in most NMRAs and only a few are prequalified by the "World Health Organization (WHO)" - this is according to the report on the situational analysis of medicines registration harmonization in Africa for ECOWAS done in 2011 (Kamwanja et al. 2011); shortage of qualified personnel, transportation and other resources limits the number and quality of GMP inspections; the assessment procedures for the issuance of marketing authorization are often administrative rather than technical in most NMRAs because there are limited resources in terms of human expertise and other resources for the technical review of dossiers; only very few NMRAs in the region have the expertise to monitor clinical trials of new drugs and vaccines for the treatment of diseases such as malaria, HIV and Tuberculosis (Ndomondo-Sigonda et al. 2017); pharmacovigillance and post marketing activities by NMRAs in this region is at its developmental stages, the focus of regulatory stewardship in the region are on pre-marketing authorization procedures instead of post-market monitoring and regulation of the distribution systems; regional decisions made by the regional body, ECOWAS, are not domesticated by member states and therefore member states rarely recognize regulatory decisions made by individual members (Kamwanja et al. 2011).

On the other hand, Pharmaceutical companies doing business in the region are faced with the following regulatory challenges (Note- these challenges are not to the same degree in all countries of the region.).

- Differences in the requirements for the registration of drugs. The requirements are as varied as the number of NMRAs in the region. Thus pharmaceutical companies have to prepare different sets of documents and dossiers for submission to different countries. This does not only add to the cost but also extends the "time to market" for researchers and manufacturers. From the point of view of capitalist entrepreneurs, this makes the region an unattractive destination for investors with medicines to sell here.

- Inefficient and unpredictable registration timelines - According to Lodge (Lodge 2004) regulatory regimes that work maintain accountability and transparency among the "parliament ... government departments, the industry, and more widely, citizens."- Most NMRAs in West Africa do not have transparent, published timelines for the registration of medicines, and they do not feel a sense of accountability to do so. Those that have do not keep to the time lines. The registration of medicines process lacks transparency. This makes planning and projecting difficult for the pharmaceutical companies. "A typical lag of 4-7 years has been recorded between first regulatory submission to a well-resourced NMRA and final approval in sub-Saharan Africa" (Ahonkhai et al. 2016). Lengthy, indeterminate and tortuous registration times are one of the reasons why companies are reluctant in supplying medicines to certain African countries. If drugs cannot get into the market, then it cannot be accessed. 
- Communication between companies and the regulators is very inadequate. NMRAs most times unilaterally make changes to guidelines and policies without seeking the inputs from stakeholders or effectively informing them. This usually results in huge cost in terms of finances and time as registrants would need to redo applications to meet new rules that were not made public

- Intellectual Property issues. For fear of compromising the IP of their products and processes, companies find it hard to trust NMRAs with sensitive information about their products. This issue is of great concern especially to multinational pharmaceutical companies. This points to the need for professionalism in regulation such that individual regulators can be trusted to understand the privacy needs registrants and demonstrate commitment to safeguarding their intellectual properties.

\section{Strategies to address these challenges}

Attaining a future of safe, quality, and effective medicines in West Africa is a shared responsibility with multiple tracks that need to be walked simultaneously. All stakeholders (the government, the regulatory systems, the manufacturers, distributors, health care providers, the global community and the patients) involved in ensuring drug manufacture and access to essential medicines in West Africa must play their implicit roles to make it happen. International development partners as part of the global community understand the significance of their roles because diseases cross borders easily and put the whole world at risk, the international development agencies bring their expertise to help poor nations improve the safety of medication for our shared global public interest.

Implementation of commitments on the part of the governments of West Africa is required to ensure access to safe, quality, and effective medicines. Many commitments to promote the health of citizens in West Africa have been made on paper (signed at conferences and summits) but are not being implemented. They should practically demonstrate that health care is a fundamental human right, and in the knowledge age has been elevated to a critical, strategic factor of production. Thus, they should review and update national policies on medicines, carefully select essential medicines in line with WHO EML, adequately provide health financing especially of the public sector and research in the private sector, ensure efficient medicines distribution systems, and make fiscal policies that give tax advantages to investors in the healthcare sector.

Governments should ensure rational use of essential medicines, as it is critical to preventing resistance and overconsumption. Since some diseases are essentially "local" governments should promote research into neglected tropical diseases (these diseases are afflicting West Africans mostly and may not be economically viable for Western companies to invest in to develop.). The role of government is important in infrastructure development because of the large amount of finance involved and it's long-term nature. It will be encouraging to manufacturing if governments provide necessary infrastructure like good roads, industrial parks with incentives, such as regular power supply, subsidies, tax holidays, free land leases, and reduction in import tariffs for pharmaceutical raw materials and machineries.. The member states of ECOWAS should patronize and encourage the patronage of locally produced pharmaceutical products to encourage and promote the growth of the pharmaceutical industry by strengthening their local competitiveness as a step toward export markets. Law reforms are necessary to clarify and protect private property rights, responsible corporate governance and consumer protection.

NMRAs in West Africa must implement systems that will accelerate the licensing and bringing to the market of quality, safe and effective medicines using a risk-based approach and closely working with manufacturers as partners in ensuring access to quality medicines. Outcomes of regulatory assessments can be shared with other NMRAs in the region (World Health Organization 2010). West African countries should establish a system of mutual recognition of regulatory decisions. Six countries (Burkina Faso, Gambia, Niger, Republic of Guinea, Senegal and Togo) have policies or legislations that provide a mandate for recognition of regulatory decisions made by other regulatory agencies (Kamwanja et al. 2011). This system should be expanded to include all West African states. Cooperation and collaboration is most needed in the fight against Substandard and Fake (SF) medicines. Collaboration and cooperation will eventually lead to the much-desired harmonization of regulatory practices in West Africa and Africa.

A critical number or mass of competent regulators must be developed now! We are running out of time. Access to safe quality and effective medicines can never be realized if we do not have enough competent regulators to do scientific systematic evaluation. The African Union and other international development partners should fund the Regional Centers Of Regulatory Excellence (RCOREs) for the training of regulators and industry practitioners. An RCORE that have been identified for training regulators and industry practitioners by NEPAD (New Partnership for Africa's Development) is the Kilimanjaro School of Pharmacy (The New Partnership for Africa's Development Regional Centers of Regulatory Excellence (RCOREs) 2018). The training program has been jointly implemented by Howard and Purdue 
Universities and sponsored by UNIDO and the Merck foundation. The training has had great impact on building the capacity of regulators. It has trained or has in training about 200 scientists from about 11 countries in Africa.

Regulatory fellowship, internship and exchange programs should be established for West African regulators where they will have hands-on trainings.

All NMRAs must adopt the principles, techniques and tools for continuous improvement of their systems to ensure the effective and efficient delivery of their mandates.

Other actions that can be taken by NMRAs are -

- Improve the remunerations of regulators in West Africa to prevent "brain drain" and reduce underhanded practices. They are the "gatekeepers" safeguarding the health of the populace. There is a saying in some villages in Africa "If the gatekeeper is hungry, a bait from the enemy will distract her and the enemy will invade the house".

- NMRAs in West Africa should start investing in post-marketing activities by tightly regulating the distribution system for medicines and improve on pharmcovigilance.

Medicines manufacturers can help to combat SF medicines and improve access to quality medicines by deploying technologies that have been developed to combat the counterfeiting of medicines e.g., tamper proof technologies, the use of special overt or covert features on their packaging and the use of specialized coding and identification systems that will help in the authentication of the medicines at the point of dispensing. They should also adopt new technologies to strengthen production and meet regional needs and for exports. The process of Transfer of Technology should be well exploited with reference to the provisions of relevant sections of TRIPs (Trade-Related Aspects of Intellectual Property Rights) flexibilities (West African Health Organization 2014).

The patients also have a part to play in the fight against fake and counterfeit medicines. There should be massive enlightenment and education of the public about the issue of SF. They can become "Fake Drug Informants" - all encountered cases of SF should be reported promptly to the appropriate authorities. When purchasing drugs they should seek for transaction documentation such as receipt as proof of purchase from the vendor. They should also diligently and consistently verify the authenticity of the medicines by utilizing the technologies being introduced on the packaging of medicines. For example, the National Agency for Food and Drugs Administration (NAFDAC) of Nigeria introduced the Mobile Authentication System (MAS). It was deployed in 2012 for use on all antimalarial and antibiotics (National Agency for Food and Drugs Administration and Control Mobile Authentication Service (MAS) 2018). The MAS empowers consumers to confirm the authenticity of medicines before purchase and use. It is a simple strategy for combating SF medicines. Consumers must stop buying medicines from non-professionals- peddlers and hawkers. All medicines should be from approved facilities. Their patronage of locally manufactured medicines will also help the growth of local manufacturers.

\section{Recent activities of international partners in West Africa to ensure access to quality medicines}

The international development partners such as the WHO, USP, UNIDO, World Bank, Bill and Melinda Gates Foundation etc. are involved in many initiatives in Africa to help improve access to safe, quality and effective medicines. A few of them are highlighted below

- The harmonization efforts in West Africa and Africa being jointly promoted by a group of partners WAHO (for the West African regional economic community), NEPAD (the African Union's technical agency for the implementation of medicines regulatory harmonization in Africa), African Union Commission, Pan African Parliament, the United Kingdom Department for International Development, Clinton Health Access Initiatives, WHO (providing the technical support) and funded by the World Bank and the Bill and Melinda Gates foundation is highly celebrated and anticipated to resolve many of the issues facing medicines regulation in West Africa. The overall aim of the African Medicines Regulations Harmonization Initiative (AMRH) is "To improve public health by increasing rapid access to safe and effective medicines of good quality for the treatment of priority diseases" (NEPAD and WHO 2017) and specifically "To reduce the time taken to register essential medicines" (NEPAD and WHO 2017). The potential benefits of the African Medicines Regulations Harmonization Initiative (AMRH) includes the building of regulatory capacity, efficient use of scarce resources, shortened timelines for the registration of essential medicines, industries will prepare only one set of documents for applying to multiple countries, faster access of essential medicines to the communities (NEPAD and WHO 2017). This initiative will help improve access to medicines needed for the Neglected Tropical Diseases and the monitoring of clinical trials for new chemical entities.

- The Pharmaceutical Manufacturing Plan for Africa (PMPA) is another laudable venture. The PMPA was adopted by the Conference of African Ministers 
of Health in April 2007 and was endorsed by the Heads of State and Government in Accra in July 2007 (The African Union Commission 2012). According to the African Union Commission, the main objectives of the PMPA venture is "to increase access to affordable quality medicines and to ensure a sustainable supply which will provide improved public health out-comes as well as deliver associated economic development." (The African Union Commission 2012). Its business plan includes the implementation of a "GMP road Map" (The African Union Commission 2012). The African Union Commission is working with UNIDO to implement the GMP road map. It is hoped that this venture will build the capacity of local Pharmaceutical manufacturing facilities helping them to meet international standards in the manufacture of medicines and thus alleviate the issue of substandard medicines in Africa. The GMP road Map is "a riskbased, phased approach to WHO GMP compliance" which involves 3 steps: Collecting baseline data on existing manufacturing practices, evaluation of gathered information and identification of the main common technical challenges and Design of a GMP roadmap based on the evaluation results (United Nations Industrial Development Organization 2015)

- Other initiatives include the training and support of regulators and industry practitioners by the USP.

\section{Conclusions}

The journey to sustainable manufacturing and access to safe, quality, and effective medicines in Africa seems long, arduous and risky, and the end seems too far off. However, as the common saying goes - "the journey of a thousand miles always begins with one determined and purposeful step". Africans and to be specific, West Africans have started the long walk to providing safe, quality and effective medicines for its people. The steps should be progressive and fast because lives are involved. This article has highlighted the challenges, which are numerous and seem mountainous - lack of adequate support from the government, human resources issues, relatively weak regulatory capacity, medicines manufacturing challenges. However, with the current initiatives - the African Medicines Regulations Harmonization, the PMPA, the GMP Road Map - being implemented, the goal can be achieved. All stakeholders - the government, NMRAs, manufacturers, regulatory consultants, the patient and development partners must work together in an intricate web of activities to overcome these challenges.

\section{Abbreviations}

AMRH: African Medicines Regulations Harmonization Initiative; ECOWAS: The Economic Community of West African States; EML: Essential Medicines List; GDP: Gross Domestic Product; GERD: Gross domestic Expenditure on
Research and Development; GMP: Good Manufacturing Practice; HDI: Human Development Index; HIV/AIDS: Human immunodeficiency Virus, Acquired immunodeficiency Syndrome; HLTF: High Level Task Force on Innovative International Financing for Health Systems; LDC: Least Developed Countries; MA: Marketing authorization; MAS: Mobile Authentication System; MDG: Millennium Development Goal; NAFDAC: National Agency for Food and Drugs Administration of Nigeria; NCE: New Chemical Entities; NEPAD: New Partnership for Africa's Development; NMRA: National Medicines Regulatory Authority; NTD: Neglected Tropical Diseases; OECD: Organization for Economic Cooperation and Development; PEPFAR: President's Emergency Plan For Aids Relief; PHC: Primary Health Care; PMPA: The Pharmaceutical manufacturing Plan for Africa; QMS: Quality management systems; R\&D: Research and development; RCORE: Regional Centers Of Regulatory Excellence; SDG: Sustainable Development Goals; SF: Substandard and falsified; SWAC: Sahel and West African Club; TRIPs: Trade-Related Aspects of Intellectual Property Rights; UEMOA: West African Economic and Monetary Union; UIS: UNESCO Institute for Statistics; UN: United Nations; UNCoLSC: UN Commission on Life-Saving Commodities for Women and Children; UNCTA: United Nations Conference on Trade and Development; UNESCO: United Nations Educational, Scientific and Cultural Organization; UNIDO: United Nations Industrial Development Organization; USP: United States Pharmacopeia; WAHO: West African Health Organization; WHO: World Health Organization

\section{Acknowledgements}

The author gratefully acknowledges Paddy Shivanand and Mehran Yazdanian for reviewing this article and giving their expert candid opinion.

\section{Authors' contributions}

AE researched, wrote and approved the final manuscript.

\section{Authors' information}

The author is a PhD student in the Biotechnology Innovation and Regulatory Science (BIRS) program of the Technology Department of Purdue University. She has a Pharmacy background and has worked with the Nigerian National Agency for Food and Drugs Administration and Control (NAFDAC) for 18 years.

Funding

The author received no funding for this article.

\section{Availability of data and materials}

The information presented is summaries of the materials referenced.

\section{Competing interests}

The author declares that she has no competing interests.

The views, thoughts and opinions presented are those of the author and do not represent the opinion of any organization that I have been, am now, or will be affiliated.

Received: 5 April 2019 Accepted: 8 July 2019

Published online: 05 August 2019

\section{References}

Adepoju P (2017) Here's a breakdown of Nigeria's 2018 budgetary allocation for health - HealthNews.NG. HealthNews.ng, Ibadan

Africa Hunger Facts, Africa Poverty Facts - World Hunger News. https://www. worldhunger.org/africa-hunger-poverty-facts-2018/. Accessed 21 Feb 2019

African Health Observatory (2013) Health financing in the African region. World Health Organization http://www.aho.afro.who.int/en. Accessed 24 Feb 2018

African Health Stats. (2016). https://www.africanhealthstats.org/cms/?pagename= indicator\&indicator=HF5. Accessed 20 May 2018

Ahonkhai V, Martins FS, Portet A, Lumpkin M, Hartman D (2016) Speeding access to vaccines and medicines in low- and middle-income countries: a case for change and a framework for optimized product market authorization. PLoS One 11(11):e0166515. https://doi.org/10.1371/journal.pone.0166515

Ball D, Roth S, Parry J (2016) Better regulation of medicines means stronger regional health security strengthening and convergence of national regulatory agencies has benefits beyond country borders. Asian Development Bank, Phillipines

Beegle K, Christiaensen L, Dabalen A, Gaddis I (2016) Poverty in a rising Africa. World Bank, Washington DC. https://doi.org/10.1596/978-1-4648-0723-7 
Berger $M$ et al (2010) Strengthening pharmaceutical innovation in Africa. Council on Health Research for Development (COHRED); New Partnership for Africa's Development (NEPAD) http://apps.who.int/medicinedocs/ documents/s18255en/s18255en.pdf. Accessed 22 Feb 2019

Blackstone EA, Fuhr JP Jr, Pociask S (2014) The health and economic effects of counterfeit drugs. Am Health Drug Benefits 7:216-224

Clark RC (2008) Building expertise: cognitive methods for training and performance improvement. Pfeiffer, San Francisco

COUNTERFEIT AND FAKE DRUGS AND UNWHOLESOME PROCESSED FOODS (MISCELLANEOUS PROVISIONS) ACT. https://www.unodc.org/res/cld/ document/nga/counterfeit-and-fake-drugs-and-unwholesome-processedfood-act_html/Nigeria_Counterfeit_and_Fake_Drugs_and_ Unwholesome_Processed_Food_Act.pdf. Accessed 11 Jan 2018

Creese A (2003) Shedding light on medicines prices, vol 33. World Health Organization, Switzerland

Defor S, Kwamie A, Agyepong IA (2017) Understanding the state of health policy and systems research in West Africa and capacity strengthening needs: scoping of peer-reviewed publications trends and patterns 1990-2015. Health Res Policy Syst 15:55. https://doi.org/10.1186/ s12961-017-0215-7

Dying from lack of medicines | Africa Renewal Online. (2019). https://www.un org/africarenewal/magazine/december-2016-march-2017/dying-lackmedicines. Accessed 21 Feb 2019

ECOWAS-SWAC/OECD (2007) Atlas on regional integration in West Africapopulation series: demographic trends. Organization for Economic Co-operation and Development http://www.oecd.org/regional/ atlasonregionalintegrationinwestafrica.htm. Accessed 2 May 2018

Federal Ministry of Health Nigeria (2016) Essential medicines list Nigeria 2016, 6th edn. The Federal Ministry of Health, Abuja

Kamwanja L, Saka J, Awotedu A, Fute I, Ndomondo-Sigonda M (2011) Situation analysis study on the medicines registration harmonization in Africa final report for the economic community of West African States. New Partnership For Africa's Development https://www.nepad.org/publication/situationanalysis-study-medicines-registration-harmonisation-africa-final-report-2. Accessed 14 Mar 2018

Levitin DJ (2008) This is your brain on music: understanding a human obsession. Atlantic, London

Lodge M (2004) Accountability and transparency in regulation: critiques, doctrines and instruments. In: Jordana J, Levi-Faur D (eds) The politics of regulation: institutions and regulatory reforms for the age of governance. E. Egar, Cheltenham

Millennium development goals indicators. (2000). http://mdgs.un.org/unsd/mdg/ host.aspx?Content=indicators/officiallist.htm. Accessed 23 Feb 2018

Moran M, Guzman J, McDonald A, Wu L, Omune B (2010) Registering new drugs: the African context. New tools for new times. The George Institute For International Health http://apps.who.int/medicinedocs/documents/s17764en/ s17764en.pdf. Accessed 2 May 2018

Mugiraneza JC (2009) Is the World Health Organization model list of essential drugs relevant to member states? National essential drugs lists of selected African countries in comparative perspective. World Health Organization http://apps. who.int/medicinedocs/en/m/abstract/Js16786e/. Accessed 24 Feb 2018

National Agency for Food and Drugs Administration and Control Mobile Authentication Service (MAS). https://www.nafdac.gov.ng/our-services/ pharmacovigilance-post-market-surveillance/mobile-authentication-servicemas/. Accessed 29 Dec 2018

Ndomondo-Sigonda M, Miot J, Naidoo S, Dodoo A, Kaale E (2017) Medicines regulation in Africa: current state and opportunities. Pharmaceut Med 31:383. https://doi.org/10.1007/s40290-017-0210-x

NEPAD, WHO (2017) African Medicines Registration Harmonisation (AMRH) initiative: summary, status and future plans. The New Partnership for Africa's Development (NEPAD) \& the World Health Organization (WHO). World Health Organization http://apps.who.int/medicinedocs/en/d/Js2 0130en/. Accessed 26 Dec 2017

Nwaka S et al (2010) Developing ANDI: a novel approach to health product R\&D in Africa. https://doi.org/10.1371/journal.pmed.1000293

Political Map of West Africa - Nations Online Project. https://www.nationsonline. org/oneworld/map/west-africa-map.htm. Accessed 22 Feb 2019

Population | West Africa. https:/eros.usgs.gov/westafrica/node/156. Accessed 21 Feb 2019

Sampat BN (2009) Academic patents and access to medicines in developing countries. Am J Public Health 99:9-17. https://doi.org/10.2105/ajph.2007.128769

Sustainable development goals. http://www.un.org/sustainabledevelopment/health/. Accessed 13 Mar 2018
The African Union Commission (2012) Pharmaceutical manufacturing plan for Africa: business plan. African Union Commission and United Nations Industrial Development Organization http://apps.who.int/medicinedocs/en/ m/abstract/Js20186en/. Accessed 27 Dec 2018

The New Partnership for Africa's Development Regional Centers of Regulatory Excellence (RCOREs). https://www.nepad.org/publication/regional-centresregulatory-excellence-rcores. Accessed 27 Dec 2018

Transparency International - Corruption Perceptions Index 2017. @anticorruption. https://www.transparency.org/news/feature/corruption_perceptions_index_2017. Accessed 21 Feb 2019

UNESCO Institute for Statistics - Literacy,. http://uis.unesco.org/en/topic/literacy. Accessed 21 Feb 2019

United Nations (2015) Millennium development goal 8 taking stock of the global partnership for development MDG gap task force report 2015. United Nations, New York

United Nations Conference on Trade and Development (2016) The least developed countries report 2016. United Nations, New York and Geneva

United Nations Department of Economic and Social Affairs Population Division (2017) World population prospects: the 2017 revision, key findings and advance tables. Working paper no. ESA/P/WP/248. United Nations https://esa.un.org/unpd/wpp/publications/Files/WPP2017_ KeyFindings.pdf. Accessed 2 May 2018

United Nations Development Group (2003) Indicators for monitoring millennium development goals definitions rationale concepts and sources. United Nations, New York

United Nations Development Program (2016) African human development report: accelerating gender equality and women's empowerment in Africa. United Nations Development Program http://www.undp.org/content/undp/ en/home/librarypage/hdr/2016-africa-human-development-report.html. Accessed 2 May 2018

United Nations Educational, Scientific and Cultural Organization - Literacy and Non-Formal Education. http://www.unesco.org/new/en/dakar/education/ literacy/. Accessed 2 May 2018.

United Nations Industrial Development Organization (2015) White paper on UNIDO's GMP road map concept. United Nations Industrial Development Organization http://apps.who.int/medicinedocs/en/m/abstract/Js22465en/. Accessed 27 Dec 2018

Uzochukwu BSC (2017) Primary health care systems (PRIMASYS): case study from Nigeria. World Health Organization https://www.who.int/alliance-hpsr/ projects/alliancehpsr_nigeriaprimasys.pdf?ua=1. Accessed 22 Feb 2019

West African Health Organization (2014) The Economic Community of West African States (ECOWAS) regional pharmaceutical plan. WAHO Essential Medicines and Vaccines Programme

West African Health Organization. The Economic Community of West African States (ECOWAS) regional pharmaceutical plan WAHO/Technical Document/ 04.14. WAHO Essential Medicines and Vaccines Programme. https://Www. unido.org/sites/default/files/2016-01/ECOWAS_Regional_Pharmaceutical_ Plan_0.pdf. Accessed 11 Mar 2018.

WHO (2015) WHO | The world medicines situation report. WHO https://www. who.int/medicines/areas/policy/world_medicines_situation/en/index.html

WHO Regional Office for Africa (2013) State of health financing in the African region. World Health Organization http://www.afro.who.int/ sites/default/files/2017-06/state-of-health-financing-afro.pdf. Accessed 24 Feb 2018

World Health Organization (2004) Equitable access to essential medicines: a framework for collective action - WHO policy perspectives on medicines, No. 008, March 2004. World Health Organization http://apps.who.int/ medicinedocs/en/d/Js4962e/1.1.html. Accessed 24 Feb 2018

World Health Organization (2010) Assessments of medicines regulatory systems in sub-Saharan Africa. World Health Organization http:// apps.who.int/medicinedocs/documents/s17577en/s17577en.pdf. Accessed 28 Feb 2018

World Health Organization (2011) The world medicines situation report. World Health Organization http://www.who.int/medicines/areas/policy/world_ medicines_situation/en/. Accessed 18 Jan 2018

World Health Organization (2015) Survey of the quality of medicines identified by United Nations Commission on Life-Saving Commodities for women and children. World Health Organization http://apps.who.int/medicinedocs/en/m/ abstract/Js23209en/. Accessed 15 Mar 2018

World Health Organization Global Health Expenditure Database. http://apps.who. int/nha/database/ViewData/Indicators/en. Accessed 20 May 2018. 
World Health Organization Global Health Observatory. https://www.who.int/gho/ maternal_health/countries/en/. Accessed 15 Mar 2018.

World Health Organization Neglected Tropical Diseases. World Health Organization. http://www.who.int/neglected_diseases/diseases/summary/en/. Accessed 5 May 2018

World Health Organization Nigeria. http://www.who.int/countries/nga/en/. Accessed 24 Feb 2018.

\section{Publisher's Note}

Springer Nature remains neutral with regard to jurisdictional claims in published maps and institutional affiliations.

\section{Submit your manuscript to a SpringerOpen ${ }^{\mathcal{O}}$} journal and benefit from:

- Convenient online submission

- Rigorous peer review

- Open access: articles freely available online

- High visibility within the field

- Retaining the copyright to your article

Submit your next manuscript at $\boldsymbol{\nabla}$ springeropen.com 